\title{
Cultural taboos and performance characteristics in Japanese daily life
}

\author{
Yaping ZHANG \\ Yan'an University \\ Yan'an ,Shanxi Province, 716000, China
}

\author{
Xiao ZHANG \\ Zhen'an Vocational Education Center \\ Shang Luo,Shanxi Province 711500, China
}

\begin{abstract}
Japan has unique natural and ethnic characteristics, and it is a rich and coordination strong collectivism, and it is a rigorous nation with requirements in a variety of manners, which not only produces a very wide range of cultural taboos in exchanges between China and Japan, and impact on the world is obvious. By understanding the cultural taboo in Japan, the Japanese can learn respect and reverence for nature, and its emphasis on personal relationships is to achieve "peace" realm; we can understand Japan's unique national character, and on this basis, the promotion of understanding of Japanese culture is to reduce or eliminate contact with the Japanese during the misunderstanding, to "do as the Romans."
\end{abstract}

Keywords- Japan; life; cultural taboos

\section{INTRODUCTION}

First, in the international arena, the word "taboo" is referred to as "Taboo", the English can be written as "taboo" or "tabu", it is said to be British navigator Captain Kirk in 1777 found that the indigenous in the Pacific island of Tonga residents have a peculiar phenomenon of life, such as a number of occasions only allowed to enter the adult males, women and children will not be admitted; some things can only be used for special purposes, such as the general situation can not be used, and the violation will be punished. The indigenous dialect called it "Taboo" which actually means "taboo." Later, "taboo" word was introduced into anthropology. Taboo language is derived from the word "taboo". Ancient times, humans only know in harmony with nature, understand and transform the nature of the low capacity, often in an uncomfortable environment and atmosphere. Therefore, it can not be artificially given the nature of the phenomenon to understand the magic of Superman, and firmly believe that this magic can bring about happiness, but also can bring about disaster. Language arising out of the activities of human consciousness naturally is with the above-fantasy magic color. So, people would think that language is the source of happiness and evil and people who violated it will be punished, and some language can never be unspoken. Speaking some had to say but because of the direct words when it comes to certain parts of the body such as other people will use some other euphemistic way of expression, in order to let the other sound pleasing to the ear and reach exchange Meanwhile purposes, and also it is to each other in order to inspire, therefore, taboo language is an important component of language. Taboos in the Japanese have "ta bu", "taboo", "things bogey Mi", etc., also have "ta bu a performance," "Mi bogey" "bogey", "The taboo words" and other terms. Japanese taboo known definition is "seeing someone or something (designated person, things, plants and animals, behavior, date, time, name, etc.) with the risk of infection, such as a ban on doing something to see, touch and other acts, otherwise it will be some unimaginable disaster. If violate taboo, not only violators will suffer disaster, but also even people outside the party as well as a common body of people will suffer a disaster. "There are many taboos and customs in Japan, and therefore, by mastering certain taboos to avoid violating taboos knowledge plays a decisive role.

\section{JAPANESE WOMEN TABOOS}

Japanese women Taboos avoidance scope is frequent than men, the negative effects of female language generated by the same taboo words are also more than men. In addition, in order to avoid taboo words because women often use euphemisms, this paper discusses the relationship between Taboo and euphemism. In everyday communication among the euphemism is one way to avoid Taboos, euphemism is to avoid the use of taboo words and make the hearer accept the expression. The two can not exist in isolation, but depend on each other. Taboos can be said to generate development and promote the emergence and development of euphemism. Furthermore, for the Japanese women Taboos, avoidance and avoidance method were analyzed. On the basis of the female Taboos clearly defined, there is further study of its classified scientific and systematic. From the "appellation Taboos", "sex-related Taboos" and "dislike things taboo words" three aspects, namely Sino-Japanese Women Taboos classified analysis. In the title, the ancient Japanese believed the person's name and human safety, health and destiny has a great relationship, so people do not address him by someone else's name, women can not address her husband's name, in addition to women, "Seest thou ta" use the word very carefully. In terms of Japanese women for sexual organs associated with sex, physiological conditions, without exception, they avoid words. For things disgust, Japanese women, for the relevant vocabulary and "dead" unclean behavior, avoid more than men. Such as: In Japan, women are more special language taboos, such as "Health", "paste", "sodium restriction", "needle", "wick" and other words of taboo. As can be seen from avoiding the topic, Japanese women in avoiding the topic of taboo language of choice have some differences in some areas, but on the whole they have similarities. Finally, it is with regard to the withdrawal of Japanese women Taboos Law. It is worth noting that, in 
verbal communication, Japanese women avoid taboo words and there are a lot of ways. Through the corpus analysis tools from voice, vocabulary means, means three grammatical aspects of Japanese women Taboos avoidance analysis. In speech means, through changing tone, slightly overlapping tone sounds, the three means can effectively achieve avoiding taboo for some languages, such as Chinese women with "big" and "small" stands for "stool" and "pee." Japanese women to "su ru Circular," said to be "su su ru ru", and the "thou Connecticut つ" ke" say "thou thou Connecticut Connecticut." In terms means, through polysemy replaced loanwords borrowed and taboo words replace these three methods, it can be effective realization of certain language taboo avoidance, for example: Japanese, women often called "Suites 个 Ritz" (toilet) as "Ritz su Suites Hikaru one woods" (restroom). In terms of grammar, by shortening sentences and using pronouns we can effectively achieve the avoidance of certain language taboos, such as: it can be seen from the evasive way, Japanese women in Taboos have evasive way of choice, there are also similar to common characteristics, but in the syntax, the Japanese women is more complicated for the avoidance of taboo words. In short, it can be seen in Japanese women as a social taboo words indeed existing in a linguistic phenomenon, namely the existence of a reasonable place. Japanese women Taboos exist and they are in use evading their respective social and cultural status of women in society, physical and psychological characteristics of women are closely related. In the communication process, taboo words avoidance is achieved through euphemisms. From the point if view, woman avoids taboo words and avoids content, of course, women taboo words are included in the scope of the taboo words, these methods avoiding taboo words are universally applicable. Because women have a unique system of discourse, avoiding the content is also unique, in this paper we only discusses this issue. To say that the development of taboo words produce promotes the emergence and development of euphemism. Furthermore, the Japanese women Taboos avoidance and avoidance method were analyzed. On the basis of the female Taboos clearly defined and further study of it is classified scientific and systematic. From the "appellation Taboos", "sex-related Taboos" and "dislike things taboo words" three aspects of Japanese women taboo words were classified analysis. In the title, the ancient Japanese believed the person's name and human safety, health and destiny has a great relationship, so people do not address him by someone else's name, women can not address him her husband's name, in addition, women use "Seest thou ta" very carefully. In terms of Japanese women for sexual organs associated with sex, physiological conditions, without exception, they avoid words. For things disgust, Japanese women for the relevant vocabulary and "dead" unclean behavior avoid more than men. Such as: In Japan, women are more special language taboos, such as "Health", "paste", "sodium restriction", "needle", "wick" and other words of taboo. As it can be seen from avoiding the topic, the two countries avoided the topic of women in the Taboos of choice, while having some differences in some areas, but on the whole they have similarities. Finally, it is with regard to the withdrawal of Japanese women Taboos Law.

\section{METHODS OF FEMALE LANGUAGE TABOOS}

In verbal communication, there are a lot of ways for Japanese women avoid taboo words. Through the corpus analysis tools from voice, vocabulary means, means of grammar, we are form the three aspects of Japanese women Taboos avoidance analysis. In speech means, through changing tone, slightly tone reduplicated three tools can be effectively realized avoid certain language taboos, such as: Japanese women to "su ru Circular," said to be "su ru su ru", and the "thou Connecticut づ ke," said into the "thou thou Connecticut Connecticut." In terms means, through polysemy replaced loanwords borrowed and taboo words are to replace, these three methods can be effective realization of certain language taboo avoidance, for example: Japanese, among women often called "Suites $\}$ Ritz" (toilet) as "Ritz su Suites Hikaru one woods" (restroom). In terms of grammar, by shortening sentences and the use of pronouns we can effectively achieve the avoidance of certain language taboos, such as: As can be seen from the evasive way, the two women are at the Taboos evasive way of choice, there are common characteristics similar, but in the use of grammar, Japanese women are more complex to avoid Taboos. In short, it can be seen Japanese women as a social taboo words indeed existing in a linguistic phenomenon, namely the existence of a reasonable place. Japanese women in the presence and use of taboo words in their respective avoid all social and cultural status of women in society; physical and psychological characteristics of women are closely related. In the communication process, taboo words avoidance is achieved through euphemisms. And, from a woman avoid taboo words and avoid content point of view, of course, women taboo words are included in the scope of the taboo words, these methods avoiding taboo words are universally applicable. Because women have a unique system of discourse, avoiding the content is also unique.

\section{TABOO ON CALL}

Ancient Japanese believe that the human soul is attached to the person's name, so each of us have different personalities, once called out the names of the soul, the devil will take away from it, so the person's name and life safety is closely linked, so people do not directly call each other names, to show the greatest respect for others and protection. It was in order to protect themselves and even frequently change their names. Japanese proverb, "the name of the body wa wo table desu" (name shows the body), that's exactly what it means. Modern Japanese society taboos title on the general performance of the next title, which subordinates, superior's juniors can not address the elder's name, the reason is the mysterious force from primitive society to blindly worship and awe the development rights to the reality. Japanese think long name is to address him on the extremely impolite and should be taboo. Modern Japanese in interpersonal call each other when the name and it is often used as a means of appellation. But according to the different 
needs of respectfulness plus suffixes, there are several different ways. "Tanaka". for example, is generally a very respectable exchanges call for a "Tanaka ", expressing respect for the older generation; more common is "Tanakasan", generally the same generation of people can use to call the most used, and scope is the greatest; "Tian Zhongjun" is used to address the younger, male ones; for the friends whose relations are very close, sometimes you can refer to "Tanaka." In the workplace, it is directly subordinate to the higher increase in duties behind its name, such as "Tanaka minister" to show their respect.

\section{CONCLUSIONS}

Each country according to its own national conditions and certain nationals living habits, local customs, etc. forms a distinctive national culture. From the Japanese in life etiquette and cultural taboos, we can understand some of the national character of the Japanese, and the Japanese pursuit among people "and" mutual courtesy between the national cultures is very commendable. Sino-Japanese cultural exchanges, it is understood the Japanese etiquette and taboos are associated with a unique culture, to "do as the Romans", create peaceful relationships for the exchange of various aspects of Japanese culture to make its own contribution.
ACKNOWLEDGEMENT

2014 Yan'an University university research projects "Sino Japanese Comparative Study of personal names" taboo No. YDQ2014-02

\section{References}

[1] Zhao Chaomin cultural taboos of daily life in Japan [J] Lanzhou Institute of Education, 2012,03: 69-70.

[2] Zhang Xin from Chinese and Japanese cultural taboos Taboos[D]. Shandong Normal University, 2012.

[3] Liu Yuanzhi. Yantai Terre 'Taboos [D]. Central University for Nationalities, 2008.

[4] Li Yan. Intercultural Communication Studies and Western traditional festival taboo [D].Qufu Normal University 2013.

[5] Xu ZuoXiu cultural taboos and aesthetic[D]. Lu Tung University, 2012

[6] Niu jiing. Chinese and Japanese language Female Taboos[D]. Jilin University, 2011.

[7] Cai Yanan research [D]. Characteristics of Japanese animation industry. Shandong University,2013. 